\title{
Crescimento e colonização micorrízica do tomateiro IPA06 inoculado com fungos micorrízicos arbusculares em substrato orgânico
}

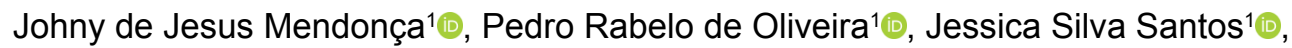
Jacilene Francisca Souza Santos ${ }^{1} \oplus$, Geovania dos Santos Menezes ${ }^{1} \oplus$, France Mário Costa $^{1} \oplus$, Andréa Verônica Gobbi Barbosa ${ }^{1}\left[{ }^{\circ}\right.$, Regina Helena Marino ${ }^{1}[0$

\footnotetext{
${ }^{1}$ Universidade Federal de Sergipe, Departamento de Engenharia Agronômica, São Cristovão, SE, Brasil. E-mail: mendonca.johny@yahoo.com.br; rabelo07@hotmail.com; jsksantos1991@gmail.com; jacilenesantos_14@hotmail.com; geovaniaa.menezes@gmail.com; france.mario@hotmail.com; andreagobbi@gmail.com; rehmarino@hotmail.com
}

RESUMO: O tomateiro IPA06 é uma variedade que apresenta frutos resistentes ao transporte e adaptada ao cultivo rústico, cuja interação com fungos micorrízicos arbusculares (FMA) ainda não foi encontrada na literatura. $O$ objetivo deste trabalho foi avaliar o crescimento e a colonização do tomateiro IPA06 cultivado com FMA em substrato orgânico. 0 delineamento experimental utilizado foi inteiramente casualizado composto pelo cultivo do tomateiro IPA06 em cinco tratamentos (controle sem inóculo fúngico e quatro inoculantes de fungos micorrizicos: UFLA05 - Gigaspora albida, UFLA351 - Rhizoglomus clarum, UFLA372 - Claroideoglomus etunicatum e UFLA401 - Acaulospora morrowiae), em substrato orgânico, com 10 repetições. Os FMAs inoculados influenciam apenas no período de germinação das sementes do tomateiro. $O$ emprego de substrato orgânico não inibe a colonização do tomateiro por FMAs. A colonização micorrízica do tomateiro IPA06 não garante incremento na biomassa vegetal, mas favorece a precocidade no florescimento, sendo responsivo aos isolados UFLA351 e UFLA401 que podem ser utilizados como inoculantes para cultivo orgânico.

Palavras-chave: nutrição vegetal; simbiose; Solanum lycopersicum

\section{Growth and mycorrhizal colonization of the tomato IPA06 inoculated with arbuscular mycorrhizal fungi on organic substrate}

ABSTRACT: Tomato IPA06 is a variety that presents fruits resistant to transport and adapted to the rustic cultivation, whose interaction with arbuscular mycorrhizal fungi (AMF) has not yet been found in the literature. The objective of this work was to evaluate the growth and colonization of the IPA06 tomato cultivated with AMF in organic substrates. The experimental design was completely randomized by the cultivation of the IPA06 tomato in five treatments (control - without fungal inoculum and four mycorrhizal fungi inoculants: UFLA05 - Gigaspora albida, UFLA351 - Rhizoglomus clarum, UFLA372 - Claroideoglomus etunicatum and UFLA401 - Acaulospora morrowiae), in organic substrate, with 10 replicates. The AMFs inoculated influenced in the germination period. The use of organic substrate does not inhibit tomato colonization by AMFs. The mycorrhizal colonization of the IPA06 tomato does not guarantee an increase in the vegetal biomass, but it favors the precocity in the flowering, being responsive to the isolates UFLA351 and UFLA401 that can be used as inoculants for organic cultivation.

Key words: plant nutrition; symbiosis; Solanum lycopersicum 


\section{Introdução}

O tomateiro (Solanum lycopersicum L.) uma solanácea capaz de se associar com fungos micorrízicos arbusculares (FMA) pertencentes ao Filo Mucoromycota, subfilo Glomeromycotina, cujo efeito no crescimento vegetativo e na produção depende da interação da espécie micorrízica com a variedade do tomateiro (Rizvi et al., 2015; Berruti et al., 2016; Spatafora et al., 2017; Volpe et al., 2018).

No Estado de Sergipe, os produtores orgânicos de tomate utilizam a variedade IPA06, por apresentar frutos resistentes ao transporte e ser adaptado ao cultivo rústico, característica esta que pode ser potencializada com o emprego de inoculantes de fungos simbiontes, como os FMAs. Neste contexto, Chitarra et al. (2016) e Rivero et al. (2018) observaram que plantas de tomateiro micorrizadas apresentaram tolerância à seca e à salinidade. No tomateiro, estes simbiontes podem: favorecer o desenvolvimento vegetativo e reprodutivo mesmo em condições de baixa fertilidade do solo (Ortas et al., 2013; Banla et al., 2015); promover a resistência ou a tolerância a patógenos e/ou pragas (Ortega et al., 2015; Shrivastava et al., 2015; Volpe et al., 2018); melhorar a qualidade e o valor nutricional dos frutos produzidos (Hart et al., 2014; Charles \& Alonso, 2015). Por sua vez, Ziane et al. (2017) e Cruz-Koizumi et al. (2018) mencionaram que o inoculante de FMA pode ser utilizado como um biofertilizante em substituição ao adubo mineral.

O FMA, durante o seu ciclo simbiótico, pode produzir esporos, apressórios, hifas extrarradiculares, vesículas e arbúsculos. Os esporos são estruturas de sobrevivência e disseminação dos fungos, que ao germinarem produzem hifas e em seguida estruturas como os apressórios. Estes são hifas modificadas com a função de reconhecimento e adesão à célula da planta hospedeira. Na ausência do apressório, não ocorre o início da simbiose. As hifas extrarradiculares aumentam a área de absorção de água e de nutrientes, principalmente, de fósforo e de nitrogênio, elementos estes essenciais ao desenvolvimento vegetal (Hart et al., 2014; Rizvi et al., 2015; Rivero et al., 2015) e podem também contribuir para agregação das partículas do solo, devido a liberação de uma glicoproteína denominada glomalina (Silva et al., 2016).

No interior das células radiculares, as hifas podem se diferenciar e formarem os arbúsculos, que são estruturas responsáveis pela simbiose propriamente dita, onde disponibilizam o fosfato à planta e, em contrapartida, a esta transfere fotoassimilados ao fungo, com gasto de energia (van der Heijden et al., 2015). As vesículas são estruturas fúngicas produzidas pela diferenciação das hifas internas e/ou externas ao córtex, cuja função é armazenar energia, na forma de lipídeos (Jalonen et al., 2013). Entretanto, Lopes et al. (2018) verificaram que a formação de arbúsculos e de vesículas em poáceas depende da interação da espécie vegetal e da espécie micorrízica, bem como da época do ano. Da mesma forma, Rivero et al. (2015) observaram que a formação de vesículas ocorreu de forma diferenciada entre isolados micorrízicos inoculados no tomateiro.
Na produção do tomateiro, o aumento da disponibilidade de nutrientes para a planta pelo emprego de adubos minerais e/ou adubo orgânico, inibe a colonização micorrízica do tomateiro em comparação ao cultivo sem adubação mineral (Charles \& Alonso, 2015; Berruti et al., 2016). Por outro lado, Cruz-Koizumi et al. (2018) verificaram que o emprego de vermicomposto favoreceu a colonização do tomateiro verde (Physalis ixocarpa Brot. ex Horn) por FMA. Assim, considerando que o efeito dos isolados de FMA no crescimento do tomateiro depende da interação planta hospedeira x condição ambiental, este trabalho teve o objetivo de avaliar o crescimento e a colonização micorrízica do tomateiro IPA06 durante a fase de mudas e após o transplantio em substrato orgânico, visando uma alternativa aos produtores orgânicos desta hortaliça.

\section{Material e Métodos}

O delineamento experimental utilizado foi inteiramente ao acaso composto pelo cultivo do tomateiro IPA06 em cinco tratamentos (controle - sem inoculação; e inoculação com quatro isolados micorrízicos, sendo: UFLA05, UFLA351, UFLA372 e UFLA401), com dez repetições.

\section{Produção dos inoculantes fúngicos}

Os isolados fúngicos micorrízicos arbusculares (FMA) UFLA05 - Gigaspora albida (Schenck \& Smith), UFLA351 Rhizoglomus clarum (Nicolson \& Schenck) Sieved. Silva \& Oehl, UFLA372 - Claroideoglomus etunicatum (Becker \& Gerd.) Walker \& Scüßler e UFLA401 - Acaulospora morrowiae Spain \& Schenck) foram doados pelo Laboratório de Microbiologia do solo, pertencente à Universidade Federal de Lavras, Minas Gerais, Brasil.

A produção dos inoculantes micorrízicos foi realizada em solo arenoso autoclavado a 120 ㅇ C e 1 atm por 1 hora e repetido após 24 horas. Após o resfriamento, o solo foi distribuído em vasos de plástico, com capacidade aproximada de $3 \mathrm{Kg}$, previamente desinfestados com hipoclorito de sódio a 0,5\% por 20 minutos, na proporção 2:1 (solo arenoso: inóculo micorrízico). O substrato inóculo contendo como estruturas infectivas como esporos do isolado fúngico micorrízico específico, hifas e fragmentos de raízes colonizadas, foi distribuído entre as camadas de solo arenoso autoclavado. Em seguida, procedeu-se a semeadura da espécie Brachiaria decumbens Staf. como planta hospedeira. O cultivo foi realizado em estufa agrícola, com irrigação por microaspersão por 60 dias. Após este período foi realizado o corte da parte aérea da braquiária e suspensa a irrigação por 15 dias, para estimular a esporulação. O número de esporos presentes no inoculante foi determinado pelo método de peneiramento úmido, segundo a metodologia descrita por Gerdemann \& Nicolson (1963). O número médio de esporos no inoculante de UFLA05, UFLA351, UFLA372 e UFLA401 foi de $274 \pm 38,151$ $\pm 55,251,5 \pm 67,5$ e $248,5 \pm 123,5$ esporos por 100 gramas de substrato, respectivamente. O número médio de esporos dos inoculantes foi, em média, 231,3 $\pm 82,8$ esporos por $100 \mathrm{~g}$ de substrato. 
Crescimento e colonização micorrízica do tomateiro IPA06

O bioensaio para avaliação do crescimento e da colonização foi dividido em duas fases. Na fase 1, avaliouse a influência dos isolados FMAs sobre o tomateiro IPA06 durante a produção das mudas por até 42 dias da inoculação, em bandeja. Na fase 2, as mudas produzidas na fase anterior foram transplantadas para substrato orgânico acondicionado em sacos plásticos e avaliado o crescimento e a colonização após 50 dias do transplantio.

Na fase 1, o substrato de cultivo utilizado à base de terra vegetal e pó de coco comercial na proporção de 2:1 foi transferido para bandeja de isopor com 128 células e entre duas camadas do substrato adicionou-se inoculante micorrízico. No tratamento controle foi utilizado apenas o substrato orgânico (terra vegetal e pó de coco). Em seguida, foram semeadas duas sementes do tomateiro IPA06 (Feltrin Sementes Ltda.) por célula. O cultivo foi realizado em estufa agrícola com irrigação por microaspersão. O desbaste foi realizado após 15 dias da semeadura, sendo conduzida apenas uma plântula por célula e realizada adubação com 5 $\mathrm{mL}$ de solução $15-00-14$ (15\% N e $\left.14 \% \mathrm{~K}_{2} \mathrm{O}\right)$ até 42 dias da semeadura. Após este período, foram selecionadas ao acaso cinco plantas para avaliação do crescimento e colonização micorrízica.

Na fase 2, foram selecionadas cinco plantas da fase 1 e, em seguida, foi transplantada uma planta por saco contendo substrato à base de terra vegetal: pó de coco comercial (1:1) acondicionado previamente em sacos plásticos com capacidade de $3 \mathrm{Kg}$. O cultivo foi realizado por 50 dias após o transplantio, em estufa agrícola com irrigação por microaspersão. Foram realizadas adubações semanalmente com aplicações de $5 \mathrm{~mL}$ de solução $15-00-14$ por planta/saco $\left(15 \% \mathrm{~N}\right.$ e $\left.14 \% \mathrm{~K}_{2} \mathrm{O}\right)$ até a colheita.

As variáveis analisadas foram: o período de germinação, a colonização micorrízica, a altura da planta, o número de folhas, o comprimento da raiz, a massa seca da raiz, a massa seca da parte aérea, a dependência micorrízicas na fase 1 e 2 ; e o número de flores somente na fase 2.

O período de germinação, por tratamento, foi avaliado pela contagem de sementes germinadas durante 15 dias.

A altura da planta e o número de folhas foram avaliados semanalmente até a colheita na fase 1 e somente na colheita na fase 2. A altura da planta e o comprimento da raiz foram avaliados a partir do colo da planta com auxílio de uma régua milimetrada.

Para determinação da massa fresca da parte aérea e da raiz, ambos materiais foram acondicionados em sacos de papel, após a lavagem das raízes em água corrente. Para obtenção das massas secas, os materiais colhidos foram submetidos à secagem em estufa com circulação forçada de ar a $60^{\circ} \mathrm{C}$ até massa constante. A massa seca da parte aérea e da raiz foram determinadas com auxílio de balança semi-analítica.

A dependência micorrízica (DM), em percentagem, foi calculada nas variáveis de altura da planta, de comprimento da raiz, de massa seca da raiz e da massa seca da parte aérea, pela equação, $\mathrm{DM}=[(\mathrm{PM}-\mathrm{PC}) / \mathrm{PM}] \times 100$, onde $\mathrm{PM}=$ valor da variável na planta cultivada com inóculo micorrízico e $\mathrm{PC}=$ valor da variável na planta no tratamento controle (sem inóculo micorrízico). A dependência micorrízica foi classificada segundo Machineski et al. (2011), onde plantas que apresentavam valores de dependência > 75\% foram consideradas com dependência excessiva, de 50 a $75 \%$ com dependência alta; de 25 a 50\% com dependência moderada; e $<25 \%$ como dependência marginal, que não responde à inoculação micorrízica.

A colonização micorrízica foi avaliada pelo método de intersecção segundo Santos et al. (2018) após 14, 28, 42 e 92 dias após a semeadura. A colonização micorrízica foi classificada segundo Carneiro et al. (1998), em que valores de 1 a 19\%, 20 a $49 \%$ e acima de $50 \%$ foram considerados como baixa, média e elevada taxa de colonização, respectivamente.

Os dados foram submetidos à análise de variância e nos casos em que houve diferença estatística significativa foi aplicado o Teste de Tukey a $5 \%$ de probabilidade. Os dados de altura da planta, número de folhas, número de flores, colonização micorrízica foram submetidos à análise de regressão e aplicado o Teste $\mathrm{F}$ a 1 e $5 \%$ de probabilidade. $\mathrm{Na}$ análise de correlação foi aplicado o teste t a 1 e $5 \%$ de probabilidade. As análises estatísticas foram realizadas no programa Assistat.

\section{Resultados e Discussão}

Crescimento e colonização das mudas do tomateiro IPA06 com isolados UFLAs (Fase 1)

A germinação das sementes foi de $81,3 \%$ nos tratamentos de inoculação com os isolados UFLAs e sem diferença significativa do controle (sem inóculo micorrízico) (Figura 1A). Com referência ao período de germinação, a inoculação com o isolado UFLA05 resultou em germinação significativamente tardia em relação ao controle e demais isolados micorrízicos (Figura 1B), o que pode atrasar o estabelecimento da simbiose propriamente dita. Diniz et al. (2006) verificaram que a microbiolização de sementes com a mistura dos microrganismos Trichoderma viride, T. polysporhum, T.stromaticum, Beauveria bassiana, Metarhizium anisopliae e FMA inibiram a germinação das sementes de alface.

Segundo Colodete et al. (2014), o aumento do período para iniciar a simbiose do FMA com a planta hospedeira pode reduzir a viabilidade do inóculo micorrízico e diminuir a colonização micorrízica das plantas hospedeiras, pois os FMA são micro-organismos biotróficos que necessitam dos fotoassimilados disponibilizados pela planta para seu metabolismo e sua sobrevivência.

Dentre os fatores que podem influenciar na colonização micorrízica do tomateiro pode-se citar: a interação da espécie de FMA com a planta hospedeira (Ortas et al., 2013; Banla et al., 2015); o período de cultivo (Rizvi et al., 2015) e a utilização de adubos minerais e/ou orgânicos (Ziane et al., 2017).

Especificamente, no tomateiro IPA06 cultivado em substrato orgânico à base de terra vegetal e pó de coco, o atraso da germinação das sementes no tratamento UFLA05 


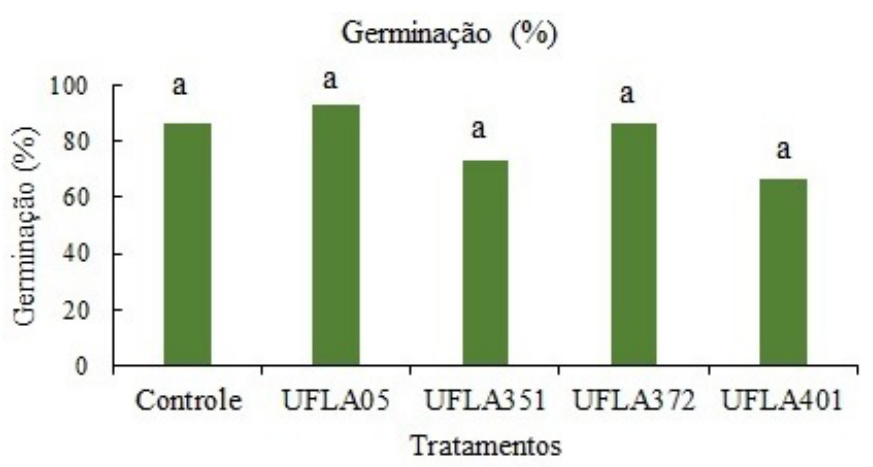

Germinação (dias)

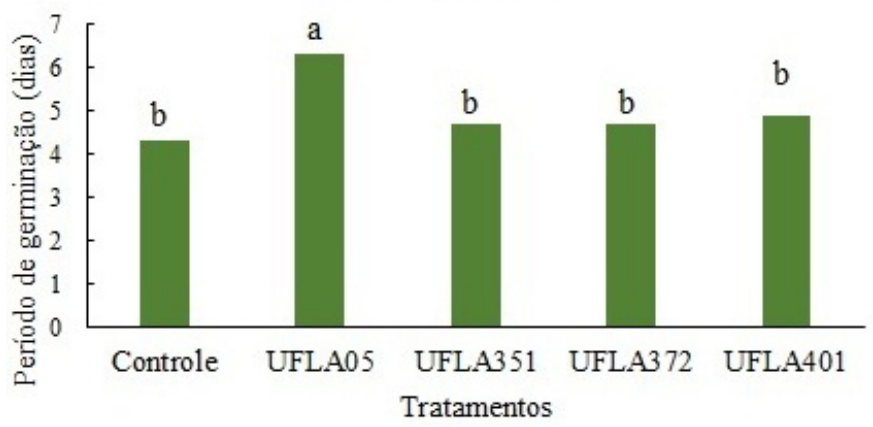

Médias seguidas de mesma letra, por tratamento, não diferem entre si pelo Teste de Tukey a $5 \%$ de probabilidade.

Figura 1. Percentagem de germinação (A) e período de germinação (B) das sementes do tomateiro IPA06 semeadas em substrato orgânico com inóculo de fungos micorrízicos arbusculares em relação ao controle (sem inoculante micorrízico).

não reduziu a taxa de colonização das plantas, que variou de $51,4 \pm 0,2 \%, 77,6 \pm 0,2 \%, 47,2 \pm 0,4 \%$ após 14,28 e 42 dias da inoculação, respectivamente. A taxa de colonização com os isolados UFLA351, UFLA372 e UFL401 variou de 40,3 a $83,8 \%$ durante o período de cultivo até 42 dias após a inoculação, valores estes próximos aos observados com UFLA05 (Figura 2). Tais valores podem ser considerados como uma colonização micorrízica média a elevada, segundo a classificação de Carneiro et al. (1998) e superiores aos valores citados por Charles \& Alonso (2015), com outra variedade de tomateiro e de espécies micorrízicas.

Merrild et al. (2013) observaram que o tomateiro 76R foi colonizado pelo fungo micorrízico Rhizoglomus irregulares (sin. Glomus intraradices) com taxa média de $87 \pm 3 \%$, valor este próximo aos $83,8 \pm 0,1 \%$ obtidos no tratamento com UFLA372 (Claroideoglomus etunicatum, sin. Glomus etunicatum) aos 28 dias de inoculação do tomateiro IPA06. Entretanto, estes autores verificaram que o aumento do período de cultivo do tomateiro favoreceu o incremento exponencial da colonização micorrízica, o que difere do comportamento observado entre o tomateiro IPA06 e os isolados avaliados. Neste trabalho houve redução significativa da taxa de colonização micorrízica entre o 28 o $(52,4$ a $83,8 \%)$ e o 42 이 dia de inoculação $(29,7$ a $55,2 \%)$, cujos dados foram ajustados à regressão quadrática $(p<0,01)$ (Figura 2). Esta redução pode estar relacionada ao fato de ter sido realizada adubação de cobertura a partir do

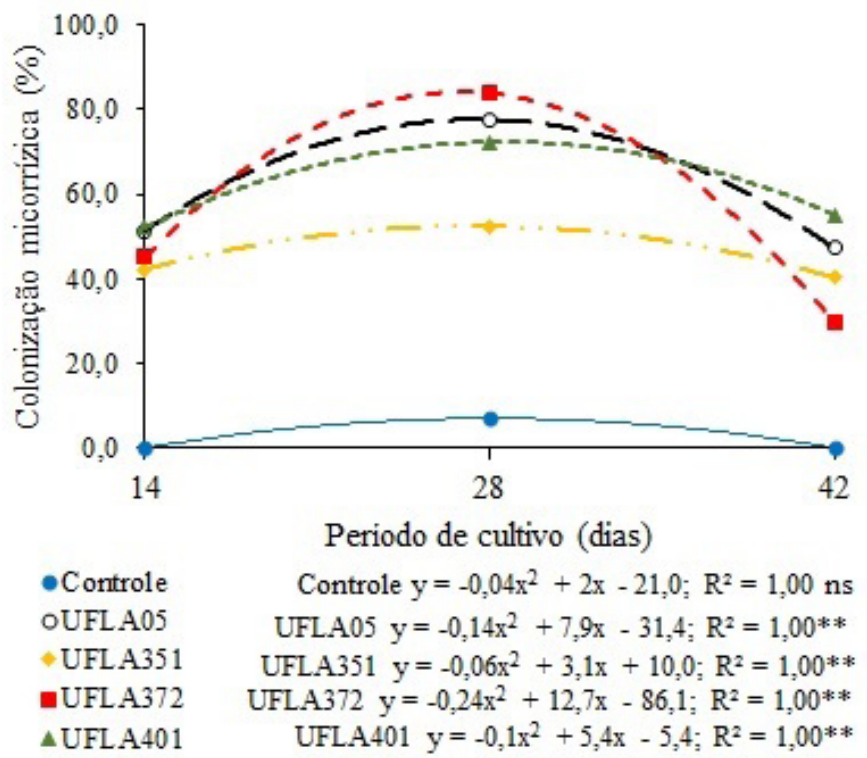

(ns) não significativo, $\left({ }^{*}\right)$ significativo a $5 \%$ de probabilidade e $\left({ }^{* *}\right)$ significativo a $1 \%$ de probabilidade pelo Teste $\mathrm{F}$.

Figura 2. Colonização micorrízica do tomateiro IPA06 cultivado com inóculo de FMA, em relação ao controle (sem inóculo), em substrato orgânico em bandeja por até 42 dias.

15o dia do plantio. Uma vez que, Banla et al. (2015) e Berruti et al. (2016) mencionaram que a adubação mineral inibiu a colonização micorrízica do tomateiro. Charles \& Alonso (2015) também observaram redução na colonização micorrízica do tomateiro com o emprego de húmus de minhoca associado ao adubo mineral, similar a este trabalho.

Na colonização micorrízica, a presença de estruturas típicas como vesículas, esporos e arbúsculos confirma a interação do FMA com a planta hospedeira, mas também pode ser um indicador do tipo de relação de simbiótica ou de competição, a depender da percentagem de arbúsculos em relação à de vesículas segundo Jalonen et al. (2013). Segundo estes autores, a relação de competição entre o FMA x planta ocorre quando a percentagem de vesículas é superior a de arbúsculos, o que resulta em uma relação baixa arbúsculo: vesícula. Por outro lado, relação alta de arbúsculo: vesícula caracteriza uma interação de benéfica ao fungo e à planta hospedeira.

No tomateiro, Rizvi et al. (2015) observaram que após 20 dias da inoculação houve intensa colonização externa e que o aumento do período de cultivo de 60 dias favoreceu a formação de arbúsculos, uma estrutura importante da disponibilidade de nutrientes entre os simbiontes. Da mesma forma, Rivero et al. (2015) mencionaram a presença de arbúsculos após oito semanas ( 56 dias) da inoculação no tomateiro.

No tratamento controle, a colonização micorrízica foi ausente no 14 e e $42^{\circ}$ dia após a inoculação, pois não foram observadas nenhuma estrutura típica de FMA. No 28 o dia da inoculação do tomateiro IPA06 foram observadas hifas extrarradiculares, vesículas e esporos, o que resultou na taxa de colonização micorrízica de $7,0 \pm 2,0 \%$. Não houve influência do aumento do período de cultivo, cujos dados não foram ajustados a nenhum modelo de regressão (Figura 2). Neste tratamento, a presença de hifas hialinas não garante que a 
colonização seja por fungos micorrízicos arbusculares, pois segundo Detmann et al. (2008), os fungos endofíticos podem apresentar hifas hialinas, os quais podem ser facilmente confundidos com FMA.

Nos tratamentos de inoculação, a colonização micorrízica foi caracterizada pela formação intensa de hifas extrarradiculares aos 14 dias da inoculação. As vesículas e os arbúsculos foram observados somente aos 28 dias da inoculação (4a semana), o que difere dos resultados citados por Rizvi et al. (2015) e Rivero et al. (2015). Neste resultado é importante considerar que se tratam de espécies micorrízicas e de variedades de tomateiro distintos, os quais podem ter influenciado na formação dos arbúsculos e das vesículas, tal como mencionado em poáceas por Lopes et al. (2018).

Guillotin et al. (2017) citaram que a colonização micorrízica do tomateiro foi controlada por genes responsáveis pela síntese de hormônios como auxina (AUX) e ácido indol-acético (AIA), que estão relacionados ao crescimento vegetal. Chitarra et al. (2016) também mencionaram o incremento na síntese do hormônio ácido abscísico (ABA) em tomateiro micorrizado, o qual pode estar correlacionado à tolerância a fatores adversos como seca e salinidade e no incremento do crescimento da planta. Rivero et al. (2018) também ressaltaram que a colonização micorrízica do tomateiro favoreceu o incremento da biomassa da raiz. Assim como, Ziane et al. (2017) mencionaram o aumento de $22 \%$ na altura da planta, $23 \%$ na massa fresca da parte aérea, $16 \%$ na massa fresca da raiz, $15 \%$ de massa seca da raiz do tomateiro industrial cultivado com FMA. Todavia, a colonização micorrízica não garante o incremento na biomassa da planta, tal como observado em tomateiro com FMA por Banla et al. (2015).

No tomateiro IPA06, a altura da planta e o número de folhas aumentaram linearmente com $o$ incremento no período de cultivo $(p<0,01)$, mas a inoculação dos isolados UFLA05, UFLA372 e UFLA401 não favoreceu o crescimento em altura da planta, quando comparado ao controle (sem inóculo micorrízico) e ao tratamento UFLA351 (Figura 3A). Quanto ao número de folhas, a inoculação com UFLA05, UFLA351 e UFLA372 reduziu significativamente esta variável em relação ao controle e ao tratamento UFLA401 (Figura 3B). Na massa seca da parte aérea, no comprimento da raiz e na massa seca da raiz não houve influência da inoculação dos isolados UFLAs (Tabela 1).

O crescimento do tomateiro IPA06 colonizado pelos isolados UFLAs, avaliado pela altura da planta, comprimento
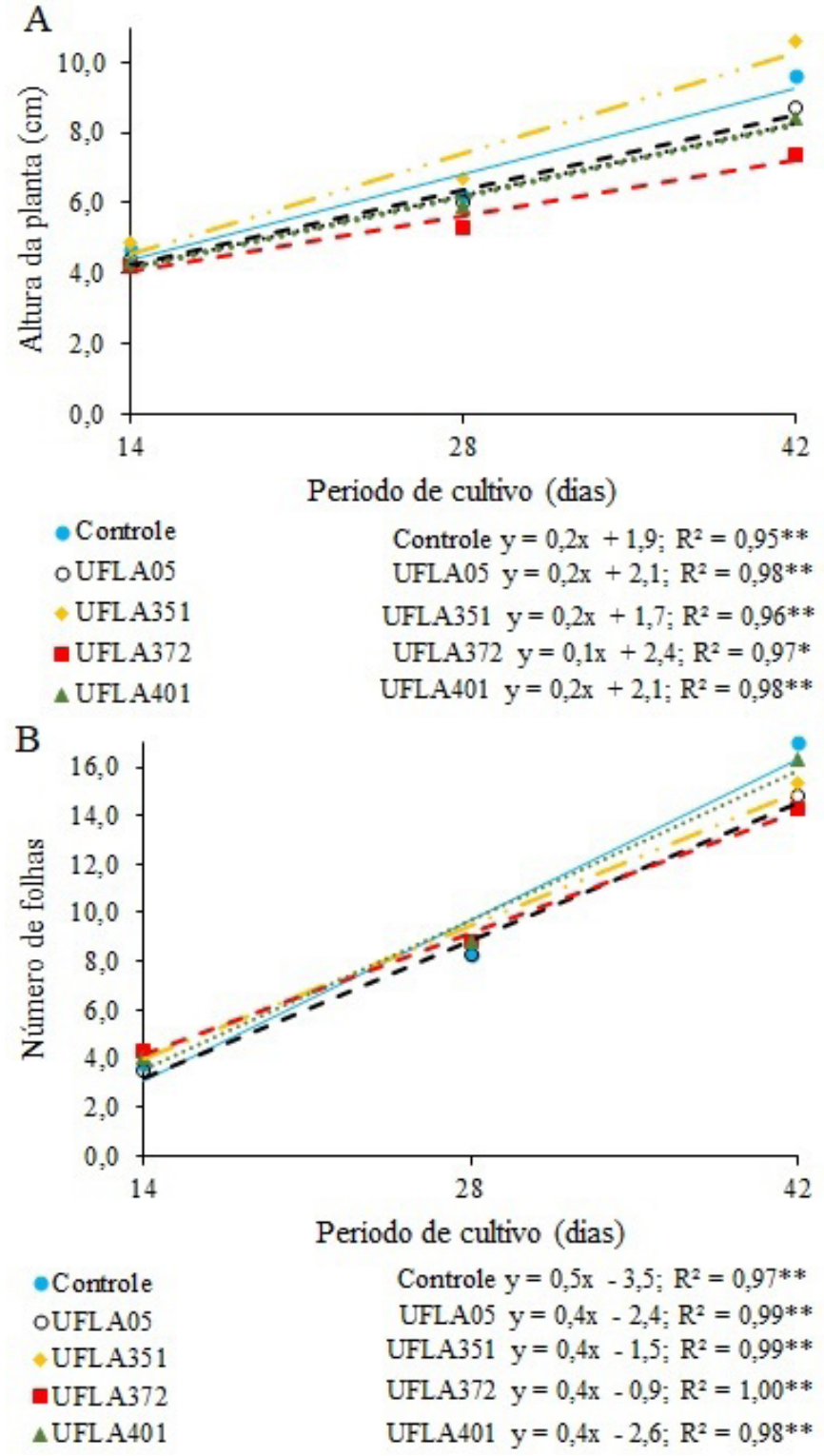

*ns - não significativo, * - significativo a $5 \%$ de probabilidade e ${ }^{* *}$ - significativo a $1 \%$ de probabilidade pelo Teste $F$.

Figura 3. Altura da planta (A) e número de folhas (B) do tomateiro IPA06 cultivado com diferentes isolados de FMA, em relação ao controle (sem inóculo), em substrato orgânico em bandeja contendo terra vegetal e pó de coco (2:1), por até 42 dias.

da raiz, massa seca da parte aérea e da raiz, não foi correlacionado com a colonização micorrízica em todos os tratamentos, exceto no cultivo com o isolado UFLA351,

Tabela 1. Altura da planta (ALT), número de folhas (NF), massa seca da parte aérea (MSPA), comprimento da raiz, massa seca da raiz (MSR) mudas de tomateiro IPA06 cultivadas com fungos micorrízicos UFLAs após 42 dias da inoculação.

\begin{tabular}{cccccc}
\hline Trat. $^{1}$ & ALT $(\mathrm{cm})$ & NF & CR (cm) & MSR (g) & MSPA (g) \\
\hline Controle & $9,6 \pm 0,3 \mathrm{a}$ & $17,0 \pm 1,4 \mathrm{a}$ & $10,9 \pm 1,9 \mathrm{a}^{2}$ & $0,03 \pm 0,01 \mathrm{a}$ & $0,10 \pm 0,02 \mathrm{a}$ \\
UFLA05 & $8,7 \pm 0,7 \mathrm{~b}$ & $14,8 \pm 1,7 \mathrm{~b}$ & $10,1 \pm 0,8 \mathrm{a}$ & $0,03 \pm 0,01 \mathrm{a}$ & $0,08 \pm 0,02 \mathrm{a}$ \\
UFLA351 & $10,6 \pm 1,7 \mathrm{a}$ & $15,3 \pm 0,3 \mathrm{~b}$ & $12,5 \pm 0,5 \mathrm{a}$ & $0,04 \pm 0,01 \mathrm{a}$ & $0,11 \pm 0,00 \mathrm{a}$ \\
UFLA372 & $7,4 \pm 0,9 \mathrm{~b}$ & $14,3 \pm 1,7 \mathrm{~b}$ & $11,0 \pm 3,6 \mathrm{a}$ & $0,04 \pm 0,02 \mathrm{a}$ & $0,08 \pm 0,03 \mathrm{a}$ \\
UFLA401 & $8,4 \pm 0,7 \mathrm{~b}$ & $16,3 \pm 1,5 \mathrm{a}$ & $10,9 \pm 1,3 \mathrm{a}$ & $0,03 \pm 0,00 \mathrm{a}$ & $0,09 \pm 0,01 \mathrm{a}$ \\
CV & 14,4 & 13,4 & 17,8 & 34,0 & 19,9 \\
\hline
\end{tabular}

Médias seguidas de mesma letra não diferem entre si pelo Teste de Tukey a $5 \%$ de probabilidade. 
que apresentou correlação negativa ( $r=-0,9575,0,01 \leq p<$ 0,05 ) entre a colonização micorrízica e o comprimento da raiz, ou seja, o aumento da colonização micorrízica reduziu significativamente o comprimento da raiz. Por outro lado, na avaliação da dependência micorrízica, o cultivo do tomateiro IPA06 com UFLA351 resultou no incremento de 10,5\% em altura da planta, $24,9 \%$ na massa seca da parte aérea, $12,7 \%$ no comprimento da raiz e $25,0 \%$ na massa seca da raiz, em relação ao controle (sem inóculo micorrízico) (Figura 4).

Este resultado demonstra que o tomateiro IPA06 foi responsivo ao isolado UFLA351 (Rhizoglomus clarum sin. Glomus clarum) com dependência micorrízica moderada segundo a classificação de Machineski et al. (2011), cujo efeito positivo pode estar correlacionado ao fato de que esta espécie é considerada generalista na simbiose (Colodete et al., 2014).

Assim, a inoculação com isolados de FMAs sobre o tomateiro IPA06 em substrato orgânico representa uma alternativa na produção de mudas com qualidade e de forma sustentável, sem a necessidade de adubos minerais. No entanto, é importante testar substratos orgânicos e isolados micorrízicos com a variedade específica, pois o efeito positivo depende da interação FMA x planta, tal como mencionado por Pipralia \& Vyas (2017) e Ziane et al. (2017).

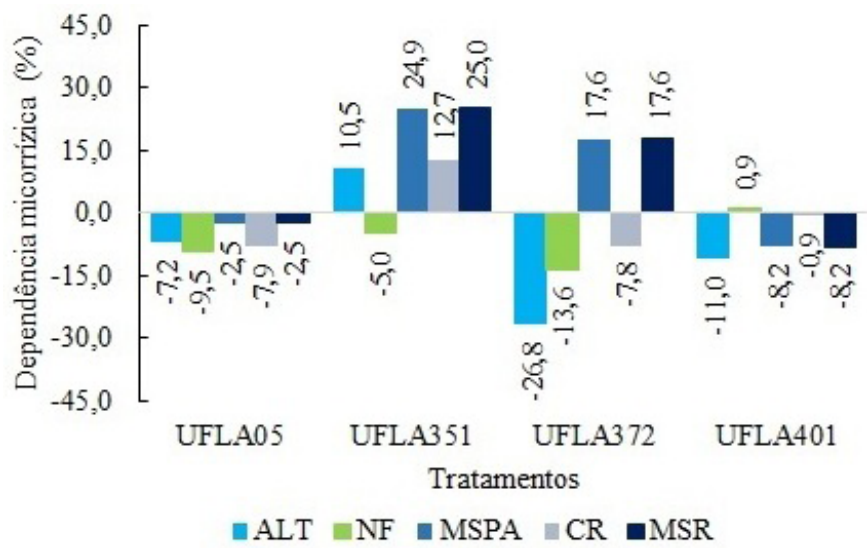

Figura 4. Dependência micorrízica do tomateiro IPA06 inoculados com isolados UFLAs em relação ao controle (sem inóculo micorrízico) nas variáveis de altura da planta (ALT), número de folhas (NF), massa seca da parte aérea (MSPA), comprimento da raiz (CR) e massa seca da raiz (MSR) após 42 dias da semeadura e da inoculação com FMAs.
Crescimento e colonização das plantas de tomateiro IPA06 inoculadas com isolados UFLAs após o transplantio (Fase 2)

As plantas do tomateiro IPA06 apresentaram taxa de colonização micorrízica de 8 a 63,6\% com isolados micorrízicos UFLAs, cujo valor médio foi $44,9 \%$ sem diferença significativa entre os tratamentos, mas significativamente superior ao controle (Tabela 2). Segundo Carneiro et al. (1998), esta taxa de colonização micorrízica pode ser considera de média a alta, tal como também foi observada por Rivero et al. (2015) com a inoculação dos FMA Rhizophagus irregulares e Funneliformis mosseae no cultivo do tomateiro. Todavia, Banla et al. (2015), plantas de tomateiro inoculadas com isolados de FMA pertencentes ao gênero Glomus apresentaram taxa de colonização micorrízica de 6 a 23\%, após 84 dias do transplantio. Charles \& Alonso (2015) observaram que a taxa de colonização micorrízica máxima do tomateiro foi de $26 \%$ após 45 dias do transplantio em substrato contendo apenas húmus de minhoca, sem adição de adubo mineral.

No controle, a taxa de colonização micorrízica de $11 \%$ foi caracterizada apenas pela presença de hifas extrarradiculares, que conforme discutido anteriormente, pode estar correlacionado com possíveis fungos endofíticos de hifas hialinas como citados por Detmann et al. (2008), as quais podem ser confundidas com as hifas dos FMA. Assim, a ausência de estruturas típicas, como os arbúsculos no tratamento controle garante que não tenham sido disponibilizados nutrientes às plantas hospedeira, como ocorre durante a simbiose do FMA com a planta hospedeira.

Em relação ao crescimento, as plantas do tomateiro nos tratamentos controle, UFLA351 e UFLA401 apresentaram incremento significativo na altura da planta, quando comparado UFLA05 e UFLA372, mas sem diferença significativa nas variáveis de massa seca da parte aérea, comprimento da raiz e na massa seca da raiz das plantas micorrizadas em relação ao controle (Tabela 2, Figura 5). Cruz-Koizumi et al. (2018) obtiveram o mesmo comportamento com plantas de tomateiro cultivadas com inóculos micorrízicos, mas em substrato à base de vermicomposto.

No tratamento controle (sem inóculo micorrízico), o aumento da altura da planta do tomateiro foi correlacionado positivamente com o comprimento da raiz $(r=0,9802 ; 0,01$ $\leq p<0,05)$, assim como também houve correlação positiva entre a massa seca da parte aérea com a massa seca da raiz $(r$ $=0,9985 ; p<0,01$ ), provavelmente devido a disponibilização de nutrientes pelo substrato orgânico e pela adubação de cobertura realizados durante o cultivo.

Tabela 2. Colonização micorrízica (CM), altura da planta (ALT), massa seca da parte aérea (MSPA), comprimento da raiz (CR), massa seca da raiz (MSR) e número de flores (NFLOR) do tomateiro IPA06 cultivado com fungos micorrízicos arbusculares UFLAs após 92 dias da inoculação.

\begin{tabular}{ccccccc}
\hline Tratamentos & CM (\%) & ALT $(\mathrm{cm})$ & MSPA (g) & CR $(\mathrm{cm})$ & MSR (g) & NFlor \\
\hline Controle & $11,2 \pm 16,9 \mathrm{~b}$ & $70,8 \pm 1,5 \mathrm{a}^{2}$ & $5,7 \pm 1,5 \mathrm{a}$ & $42,5 \pm 7,1 \mathrm{a}$ & $2,1 \pm 1,2 \mathrm{a}$ & $7,0 \pm 2,8 \mathrm{a}$ \\
UFLA05 & $43,9 \pm 14,1 \mathrm{a}$ & $66,0 \pm 9,0 \mathrm{~b}$ & $5,1 \pm 1,8 \mathrm{a}$ & $43,0 \pm 12,8 \mathrm{a}$ & $1,3 \pm 0,7 \mathrm{a}$ & $3,3 \pm 0,5 \mathrm{~b}$ \\
UFLA351 & $43,9 \pm 19,0 \mathrm{a}$ & $76,8 \pm 9,6 \mathrm{a}$ & $8,6 \pm 1,5 \mathrm{a}$ & $38,3 \pm 6,8 \mathrm{a}$ & $2,8 \pm 1,7 \mathrm{a}$ & $7,3 \pm 1,0 \mathrm{a}$ \\
UFLA372 & $43,5 \pm 15,4 \mathrm{a}$ & $56,5 \pm 13,3 \mathrm{~b}$ & $5,1 \pm 2,6 \mathrm{a}$ & $37,0 \pm 14,0 \mathrm{a}$ & $2,4 \pm 1,9 \mathrm{a}$ & $5,7 \pm 1,2 \mathrm{a}$ \\
UFLA401 & $48,4 \pm 10,6 \mathrm{a}$ & $72,5 \pm 6,1 \mathrm{a}$ & $7,1 \pm 0,5 \mathrm{a}$ & $40,0 \pm 3,7 \mathrm{a}$ & $3,7 \pm 1,1 \mathrm{a}$ & $8,7 \pm 1,7 \mathrm{a}$ \\
CV & 26,2 & 15,4 & 28,3 & 24,2 & 59,4 & 25,8 \\
\hline
\end{tabular}

Médias seguidas de mesma letra não diferem entre si pelo Teste de Tukey a $5 \%$ de probabilidade. 

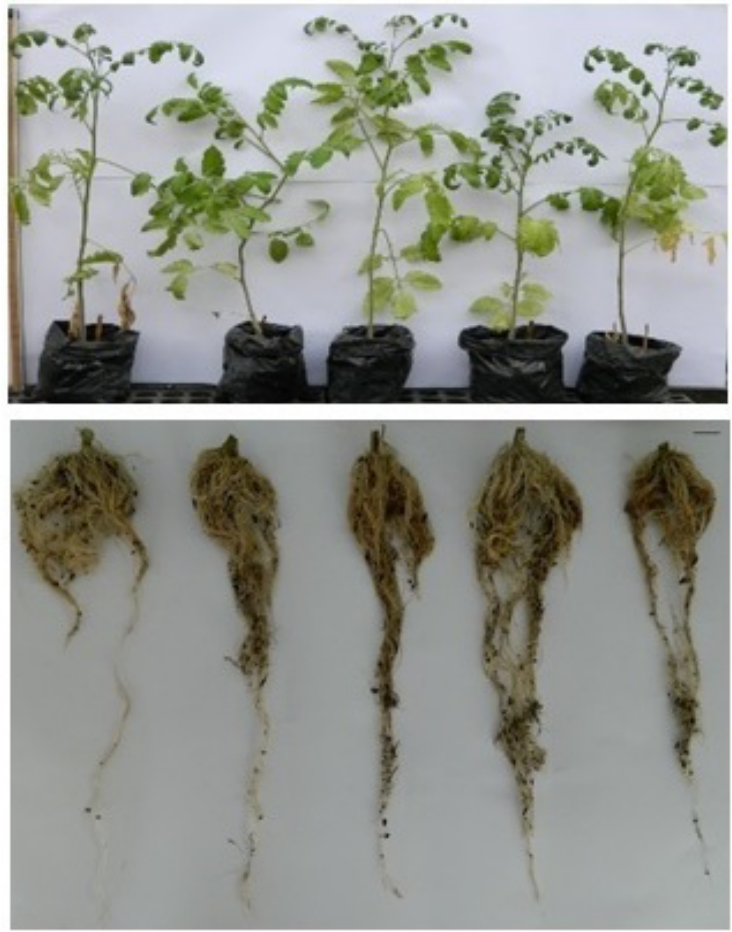

CONTROLE UFLA05 UFLA351 UFLA372 UFLA401

Figura 5. Parte aérea e da raiz das mudas do tomateiro IPA06 cultivadas com isolados UFLAs após 92 dias da inoculação.

Segundo Rivero et al (2015), a associação dos fungos micorrízicos Rhizophagus irregulares e Funneliformis mosseae promoveu o incremento na biomassa da raiz do tomateiro, devido a maior absorção de nutrientes pelas plantas micorrizadas (Rizvi et al., 2015).

No tratamento UFLA372 houve correlação positiva entre o comprimento da raiz com a massa seca da raiz $(r=0,9609$; $0,01 \leq p<0,05)$ e com a massa seca da parte aérea $(r=0,9752$, $0,01 \leq p<0,05$ ). No entanto, em todos os tratamentos, não houve correlação entre a colonização micorrízica e as variáveis analisadas.

No tomateiro cultivado com UFLA351 houve incremento de $31,2 \%$ na massa seca da parte aérea e o isolado UFLA401 aumentou em 40,9\% a massa seca da raiz do tomateiro, quando comparado às plantas no controle (sem inoculantes micorrízico) (Figura 6), o que pode estar correlacionado com o aumento de nutrientes pelas plantas micorrizadas, tal como mencionado por Rivero et al. (2015) e Rizvi et al. (2015).

Em relação ao florescimento, Banla et al. (2015) enfatizaram que a inoculação micorrízica do tomateiro com isolados Glomus sp. atrasou a emissão de flores, tendo início após 59 dias e finalizando aos 73 dias do transplantio. No entanto, CruzKoizumi et al. (2018) observaram que a colonização micorrízica não reduziu a produção de tomates quando comparado ao cultivo convencional com adubos minerais e sem FMA.

No tomateiro IPA06, o isolado UFLA05 (Gigaspora albida) promoveu redução significativa no número de flores, quando comparado ao controle e aos demais isolados UFLAs (Tabela 2). A emissão das flores ocorreu no 36 dia após o transplantio, o que caracteriza que a inoculação micorrízica pelos isolados

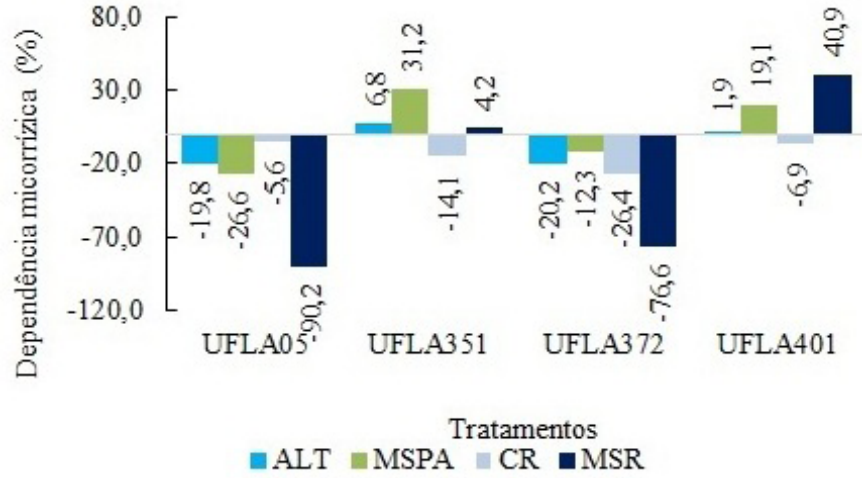

Figura 6. Dependência micorrízica do tomateiro IPA06 inoculados com isolados UFLAs em relação ao controle (sem inóculo micorrízico) nas variáveis de altura da planta (ALT), massa seca da parte aérea (MSPA), comprimento da raiz (CR) e massa seca da raiz (MSR) após 92 dias da inoculação.

UFLAs favoreceu a precocidade no florescimento, tal como também citado por Ortas et al. (2013) no tomateiro o cultivado com isolados Glomus de FMA. E ao contrário do resultado verificado por Banla et al. (2015).

De forma geral, a inoculação do tomateiro IPA06 com FMAs em substrato à base de terra vegetal e pó de coco representa uma alternativa tecnicamente viável, principalmente, para agricultura orgânica.

\section{Conclusões}

A inoculação micorrízica influência no período de germinação, mas não na percentagem de germinação das sementes do tomateiro.

O emprego de substrato orgânico não inibe a colonização do tomateiro pelos isolados UFLAs.

A colonização micorrízica do tomateiro IPA06 não garante incremento na biomassa vegetal, mas favorece o florescimento precoce.

O tomateiro IPA06 é responsivo aos isolados UFLA351 e UFLA401 e estes podem ser utilizados como inoculantes para obtenção de mudas.

\section{Literatura Citada}

Banla, E. M.; Banito, A.; Sogbedji, J. M. Effects of arbuscular mycorrhizal fungi on the production of tomato in Togo. International Journal of Biological and Chemical Sciences, v.9, n.3, p.1270-1276, 2015. https://doi.org/10.4314/ijbcs.v9i3.12.

Berruti, A.; Lumini, E.; Balestrini, R.; Bianciotto, V. Arbuscular mycorrhizal fungi as natural biofertilizers: Let's benefit from past successes. Fronties Microbiology, v.6, article 1559, 2016. https:// doi.org/10.3389/fmicb.2015.01559.

Carneiro, M.A.C.; Siqueira, J.O.; Moreira, F.M.S.; Carvalho, D.; Botelho, S. A.; Saggin-Junior, O. J. Micorriza arbuscular em espécies arbóreas e arbustivas de ocorrência no sudeste do Brasil. Cerne, v.4, n.1, p.129-145, 1998. http://cerne.ufla.br/ojs/index.php/ CERNE/article/view/608/518. 02 Mai. 2016. 
Charles, N. J.; Alonso, N. J. M. Management and use of arbuscular mycorrhizal fungi (AMF) and earth worm humus in tomato (Solanum lycopersicum L.) under Protected system. Cultivos Tropicales, v.36, n.1, p.53-62, 2015. http://scielo.sld.cu/pdf/ctr/ v36n1/en_ctr07115.pdf. 18 Jan. 2019.

Chitarra, W.; Maserti, B.; Gambino, G.; Guerrieri, E.; Balestrini, R. Arbuscular mychorrhizal symbiosis-mediated tomato tolerance to drought. Plant Signaling \& Behavior, v.11, n.7, e1197468, 2016. https://doi.org/10.1080/15592324.2016.1197468.

Colodete, C.M.; Souza, S.B.; Barbirato, J.O.; Ruas, K. F. Novas perspectivas da simbiose micorrízica e seus facilitadores transmembrânicos na interface da troca bidirecional de nutrientes minerais: revisão. Perspectivas online: biologia \& saúde, v.12, n.4, p.8-21, 2014. http://seer.perspectivasonline. com.br/index.php/biologicas_e_saude/article/view/16/406. 14 Mai. 2016.

Cruz-Koizumi, Y.P.; Alayón-Gamboa, J.A.; Morón-Rios, A.; CastellanosAlbores, J.; Aguilar-Chama, A.; Guevara, R. Effects of organic and chemical agriculture systems on arbuscular mycorrhizal fungi and green tomato production in Calakmul, Mexico. Agricultural Sciences, v.9, n.9, p.1145-1167, 2018. https://doi.org/10.4236/ as.2018.99080.

Detmann, K.S.C.; Delgado, M.N.; Rebello, V.P.A.; Leite, T.S.; Azevedo, A.A.; Kasuya, M.C.M.; Almeida, A.M. Comparação de métodos para a observação de fungos micorrízicos arbusculares e endofíticos do tipo dark septate em espécies nativas de cerrado. Revista Brasileira de Ciências do Solo, v.32, n.5, p.1883-1890, 2008. https://doi.org/10.1590/S0100-06832008000500009.

Diniz, K.A.; Oliveira, J.A.; Guimarães, R.M.; Carvalho, M.L.M.; Machado, J.C. Incorporação de microrganismos, aminoácidos, micronutrientes e reguladores de crescimento em sementes de alface pela técnica de peliculização. Revista Brasileira de Sementes, v.28, n.3, p.37-43, 2006. https://doi.org/10.1590/ S0101-31222006000300006.

Gerdemann, J.W.; Nicolson, T.H. Spores of mycorrhizal endogone species extracted from soil by wet-sieving and decanting. Transactions of British Mycological Society, v.46, n.2, p.235-244, 1963. https://doi.org/10.1016/S0007-1536(63)80079-0.

Guillotin, B.; Etemadi-Shalamzari, M.; Audran-Delalande, C.; Bouzayen, M.; Bécard, G.; Combier, J.P. SI-IAA27 regulates strigolactone biosynthesis and mycorrhization in tomato (var. MicroTom). New Phytologist, v.213, n.3, p.1124-1132, 2017. https://doi.org/10.1111/nph.14246.

Hart, M.; Ehret, D. L.; Krumbein, A.; Leung, C.; Murch, S.; Turi, C.; Franken, $\mathrm{P}$. Inoculation with arbuscular mycorrhizal fungi improves the nutritional value of tomatoes. Mycorrhiza, v.25, n.5, p.359-376, 2014. https://doi.org/10.1007/s00572-014-0617-0.

Jalonen, R.; Timonen, S.; Sierra, J.; Nygren, P. Arbuscular mycorrhizal symbioses in a cut-and-carry forage production system of legume tree Gliricidia sepium and fodder grass Dichanthium aristatum. Agroforest Systems, v.87, n.2, p.319-330, 2013. https://doi. org/10.1007/s10457-012-9553-1.

Lopes, L.J.O.; Santos, G.M.; Santos, J.S.; Santos, J.F.S.; Mendonça, J.J.; Fagundes, J.L.; Marino, R.H. Produção de propágulos micorrízicos em sorgo e/ou em braquiária. Scientia Plena, v.14, n.8, p.1-8, 2018. https://doi.org/10.14808/sci.plena.2018.086201.
Machineski, O.; Balota, E.L.; Souza, J.R.P. Resposta da mamoneira a fungos micorrízicos arbusculares e a níveis de fósforo. Semina: Ciências Agrárias. v.32, n.4, supl. 1, p. 1855-1862, 2011. https:// doi.org/10.5433/1679-0359.2011v32n4Sup1p1855.

Merrild, M.P.; Ambus, P.; Rosendahl, S.; Jakobsen, I. Common arbuscular mycorrhizal networks amplify competition for phosphorus between seedlings and established plant. New Phytologist, v.200, n.1, p.229-240, 2013. https://doi.org/10.1111/nph.12351.

Ortas, I; Sari, N.; Akpinar, C.; Yet, H. Selection of arbuscular mycorrhizal fungi species for tomato seedling growth, mycorrhizal dependency and nutrient uptake. European Journal Horticultural Science, v.78, n.5, p.209-2018, 2013. https://www.pubhort.org/ ejhs/2013/file_4044268.pdf. 18 Jan. 2019.

Ortega, E.P.; Noval, B. M. L.; Coca, B. M.; Noval, W. T. L.; Carmona, A. M.; Hernández, A.; León, O. Induction of defense mechanisms in mycorrhized tomato plants against the attack of Oidiopsis taurica (Lev.) Salm. Cultivos Tropicales, v.36, n.1, p.94-102, 2015. http:// scielo.sld.cu/pdf/ctr/v36n1/en_ctr13115.pdf. 18 Jan. 2019.

Pipralia, R.; Vyas, A. Mycorrhizal association with relationship of tomato in air and semi-arid zone of Rajasthan. The Pharma Innovation Journal, v.6, n.12, p.93-95, 2017. https://doi. org/10.21746/aps.2017.6.12.12.

Rivero, J.; Álvares, D.; Flors, V.; Azcón-Aguilar, C.; Pozo, M. J. Root metabolic plasticity underlies functional diversity in mycorrhizaenhanced stress tolerance in tomato. New. Phytologist, v.220, n.4, p.1322-1336, 2018. https://doi.org/10.1111/nph.15295.

Rivero, J.; Gamir, R.A.; Pozo, M.J.; Flors, V. Metabolic transition in mycorrhizal tomato roots. Frontiers Microbiology, v.6, article 598, p.1-13, 2015. https://doi.org/10.3389/fmicb.2015.00598.

Rizvi, R.; Iqbal, J.; Mahmood, I.; Ansari, R.A. Comparative efficacy of different arbuscular-mycorrhizal fungal spp. (AMF) on tomato (Lycopersicum esculentum Mill.). e-Journal of Science \& Technology, v.1, n.10, p. 13-26, 2015. http://e-jst.teiath.gr/ issues/issue_39/Ansari_39.pdf. 15 Jan. 2019.

Santos, T.A.C.; Menezes, G.S.; Santos, J.S.; Gois, L.S.; Nascimento, S.L. M.; Marino, R. H. Microbial Interactions in the development of the biomass of gliricidia. Revista Caatinga, v.31, n.3, p.612- 621, 2018. https://doi.org/10.1590/1983-21252018v31n309rc.

Shrivastava, G.; Ownley, B.H.; Augé, R.M.; Toler, H.; Dee, M.; Vu, A.; Köllner, T.G.; Chen, F. Colonization by arbuslar mycorrhizal and endophytic fungi enhanced terpene production in tomato plants and their defense against a herbivorous insect. Symbiosis, v.65, n.2, p.65-74, 2015. https://doi.org/10.1007/s13199-015-0319-1.

Silva, C.F.; Pereira, M.G.; Santos, V.L.; Miguel, D.L.; Silva, E.M.R. Fungos micorrízicos arbusculares: composição, comprimento de micélio extrarradicular e glomalina em áreas de mata atlântica, Rio de Janeiro. Ciência Florestal, v.26, n.2, p.419-433, 2016. https://doi.org/10.5902/1980509822743.

Spatafora, J.W.; Aime, M.C.; Grigoriev, I.V.; Martin, F.; Stajich, J.E.; Blackwell. M. 2017. The fungal tree of life: from molecular systematics to genome-scale phylogenies. Microbiol Spectrum, v.5, n.5, FUNK-00532016. https://doi.org/10.1128/microbiolspec.FUNK-0053-2016.

van der Heijden, M.G.A.; Martin, F.M.; Selosse, M-A.; Sanders, I.R. Mycorrhizal ecology and evolution: the past, the present, and the future. New Phytologist, v.205, n.4, p.1406-1423, 2015. https:// doi.org/10.1111/nph.13288. 
Volpe, V.; Chitarra, W.; Cascone, P.; Volpe, M.G.; Bartolini, P.; Moneti, G.; Pieraccini, G.; Serio, C.D.; Maserti, B.; Guerrieri, E.; Balesstrini, R. The association with two different arbuscular mycorrhizal fungi differently affects water stress tolerance in tomato. Frontiers in Plant Science, v.9, article 1480, p.1-16, 2018. https://doi.org/10.3389/fpls.2018.01480.
Ziane, H.; Meddad-Hamza, A.; Beddiar, A.; Gianinazzi, S. Effects of arbuscular mycorrhizal fungi and fertilization levels on industrial tomato growth and production. Internacional Journal of Agriculture \& Biology, v.19, n.2, p.341-347, 2017. https://doi. org/10.17957/IJAB/15.0287. 